\title{
A call to protect women's rights in Solomon Islands' forestry legislation, policy and practice
}

Tessa Minter

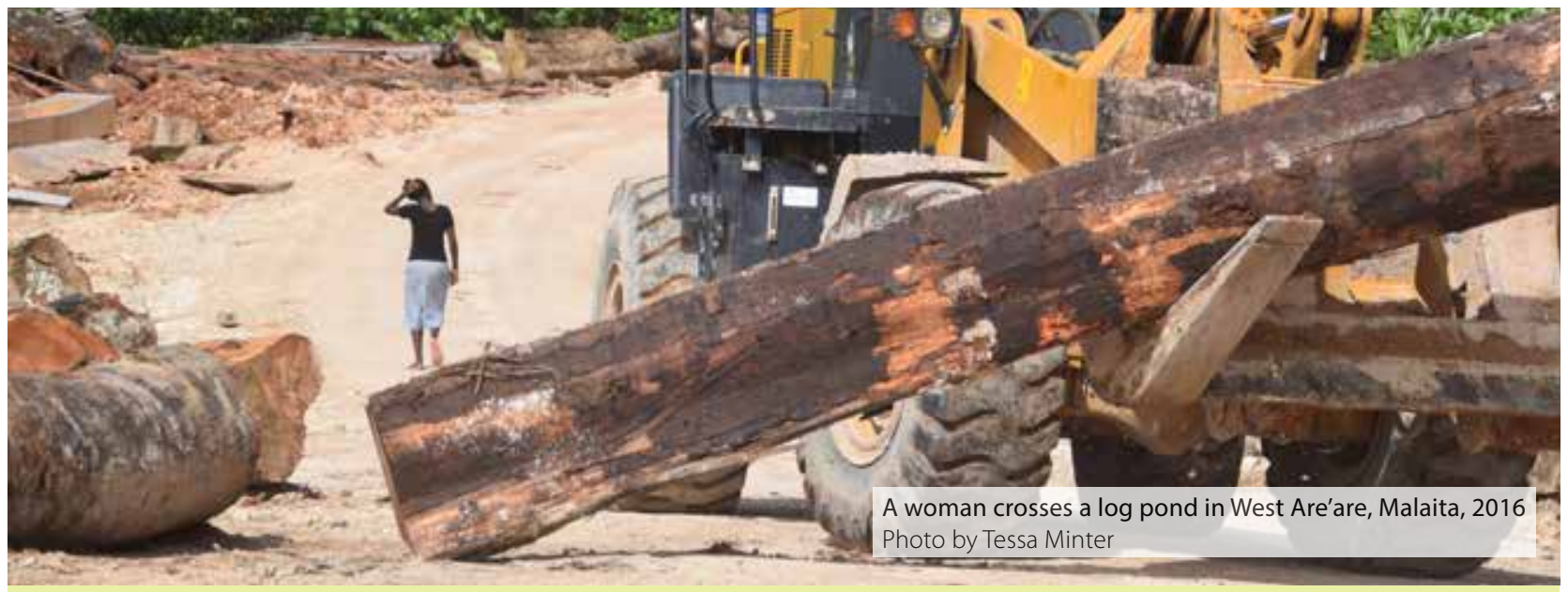

\section{Key messages}

- Gender inequality and gender-based violence are major development issues throughout Solomon Islands.

- Injustices against women and girls are particularly pronounced in the logging sector.

- Solomon Islands is making important advances towards designing policies that aim to achieve gender equity, but these advances are yet to become visible within the forestry sector.

- This info brief summarizes research on the impacts of logging operations on Solomon Islands' women and girls.

- It calls for the development of legislation, policy and practice that ensures gender equity in logging operations and offers recommendations for doing so.

- The National Forest Policy and ongoing review of the Forest Resources and Timber Utilization Act provide important opportunities to address the gender injustices that characterize the Solomon Islands' logging sector.

\section{Gender disparities in Solomon Islands}

Gender disparities form a major development challenge throughout Solomon Islands. Women and girls are severely underrepresented in public decision making,

Institute for Cultural Anthropology and Development Sociology, Leiden University political participation and paid work (MWYCFA 2016; World Bank 2019, 12). Prevalence of gender-based violence (GBV) in the country is very high: $64 \%$ of Solomon Islands' women experience physical or sexual intimate partner violence, and there are few effective means to seek help and justice in GBV cases, especially outside of urban centres (ADB 2015, xvi; Ride and Soaki 2019). 
Women also enjoy little control over land and natural resource management, which is of particular importance in rural areas, where $75 \%$ of Solomon Islanders live (FAO and SPC 2019). Women's role in decision making on, and benefit sharing from, logging is especially limited. The forestry sector has been a dominant component of Solomon Islands' economy since the 1980s. Logging operations take place on customary-owned land, which is collectively governed by mostly patrilineal and, less commonly, matrilineal clans. Even in matrilineal clans however, women's rights to land and resources are, in practice, limited to usufruct rights. Decision making regarding land use and the allocation of logging royalties is the exclusive privilege of (elderly) male clan members (FAO and SPC 2019; Kabutaulaka 2000).

\section{Gender policy in Solomon Islands}

In recent years the Solomon Islands government has endorsed various international and regional agreements to advance gender equality, including the Pacific Platform for Action on Gender Equality and Women's Human Rights (1994, 2004 and 2018-2030), the Convention on the Elimination of All Forms of Discrimination against Women (2002), and the 2030 Agenda for Sustainable Development (2015).

At the national level, several legal and policy documents have come into force and programmes have been rolled out that have the potential to contribute to addressing gender disparities. The most important of these are:

1. The Family Protection Act (2014), which criminalizes physical, sexual, psychological and economic abuse, or the threat of such abuse, between people in a domestic relationship, which includes engagement, customary, courtship or sexual relations of any duration.

2. The National Gender Equality and Women's Development Policy (2016-2020), which links national, regional and international commitments to gender equality, identifies strategic areas for action, and calls for collaboration between government organisations and NGOs to advance gender equality. The policy stresses the importance of providing quality services to women and girls in rural areas and supporting their economic empowerment.

3. The National Policy to Eliminate Violence Against Women and Girls (2016-2020), which prioritizes developing holistic prevention strategies; strengthening legal frameworks, law enforcement and the justice system; improving medical, protective and legal services; and holding perpetrators accountable.

4. The Solomon Islands National Development Strategy (2015-2035), which aspires to improve gender equality as a medium-term strategy.
The Ministry of Women, Youth, Children and Family Affairs (MWYCFA) and key civil society organizations like Vois blo Mere (Women's Voice), the Council of Women and the Women's Union, together conduct the bulk of work towards achieving the aspirations set out in the above documents. Increasingly, other government agencies recognize the importance of gender mainstreaming. This is apparent, for instance, from the Ministry of Fisheries and Marine Resources adopting a Gender Implementation Strategy in 2011, as well as a more general growing sensitivity towards gender issues within the fisheries sector (SPC 2018).

However, such advances are still to materialize in the Solomon Islands logging sector, which is governed by the Ministry of Forestry and Research (MOFR). This is despite the fact that logging operations across the country are known to further marginalize and severely harm women and girls in multiple ways (Scheyvens and Lagisa 1998; Herbert 2007; IOM 2019). The gendered impacts of logging in Solomon Islands have become pressing, to the extent that they were discussed during the UN Human Rights Council Universal Periodic Review in May 2021 (UN 2021).

With the MOFR's recent endorsement of the National Forest Policy, and given that the foremost piece of forestry legislation, the Forest Resources and Timber Utilization Act (FRTUA), is presently undergoing review, this is a timely moment to take steps towards gender equitable forestry legislation, policy and practice.

\section{Methods}

This info brief explains how logging affects women and girls, and offers recommendations for making Solomon Islands' forestry legislation, policy and practice gendersensitive and inclusive. It is based on social scientific research conducted on the island and Province of Malaita between November 2016 and December 2019. Two hundred people, half of them women, living in 14 logging concessions, were interviewed on the ways in which logging operations affected their lives. On-site observations were used to verify and complement the information gathered through interviews.

\section{Logging in Solomon Islands}

Solomon Islands has relied on industrial logging since the 1980s; it is the world's second biggest exporter of tropical logs, after neighbouring Papua New Guinea (ITTO 2019, 21). Logging operations are conducted by foreign (mostly Malaysian) companies, in collaboration with 
local licensees. The sector leans heavily on the export of unprocessed round logs, which are primarily destined for China (World Bank 2017, 53; MOFR 2020, 3).

The customary-owned forests in which logging takes place, and the adjacent marine environments, are vital for rural sustenance (Schwarz et al. 2013). Most people subsist on a combination of fishing and the cultivation of root crops, vegetables and fruit trees in swidden fields. Swidden crops are supplemented with both wild and semi-cultivated nuts, roots, leaves, fruits and fungi collected from the forest. The hunting of birds, bats, possums and rodents and the collection of frogs, lizards, freshwater snails and molluscs is additionally important, especially for inland communities. The forest also provides the timber, bamboo and canes needed for housing and other construction needs, and is a space of high cultural importance. Forests contain numerous sacred sites, many of which are off limits for resource use. These include ancestor worshipping, burial and birthing sites.

The Ministry of Forestry and Research (MOFR) and the Ministry of Environment, Climate Change, Disaster Management and Meteorology (MECDM) are mandated to regulate the logging sector. The Forest Resources and Timber Utilization Act (FRTUA 1984), which is currently under review, along with the Environment Act (1998), the Code of Logging Practice (2002) and the recently endorsed National Forest Policy (MOFR 2020), form the legal and policy basis for regulating logging operations.

However, there has long been concern about the unsustainable rate at which Solomon Islands' forests are being harvested and the consequences this has for local livelihoods, as well as for the long-term viability of the forestry sector itself (MOFR 2020). Re-entry logging in immature forests is common, and poor logging practices have resulted in highly degraded forest areas across the country (Katovai et al. 2021). Often, multiple logging companies operate adjacent to each other, but without mutual use of infrastructure. Figures 1 and 2 show how this results in a high density and haphazard creation of log ponds and logging roads on Malaita. On 1 April 2021, the Permanent Secretary of the MOFR confirmed before parliament that 435 logging licenses are currently operational, but that the ministry does not have the capacity, equipment, personnel and finances to effectively monitor these (Osifelo 2021).

Revenues from logging fall short of what they could be, because of evasion of financial obligations and under-pricing of logs (World Bank 2017). Development projects promised by logging companies (like roads, schools, clinics and water systems) are typically poorly delivered. The contribution of logging to local employment is also limited because round log production requires little in-country processing and most skilled labour is hired internationally (Minter et al. 2018).

Logging also has long-lasting fracturing impacts on social relations. Conflicts between land-owning clans and logging companies, as well as between and within clans, arise over the desirability of logging; land ownership; the distribution and use of royalties; the implementation of development projects; compensation of damage caused by logging; and the violation of cultural taboos. Such conflicts regularly lead to the abrupt departure of logging companies. They also result in deep distrust between and within land-owning clans and families, thus harming social cohesion.

While this alarming situation affects both women and men, women and girls experience specific and far-reaching negative impacts owing to their marginalization in ownership and decision making regarding land and natural

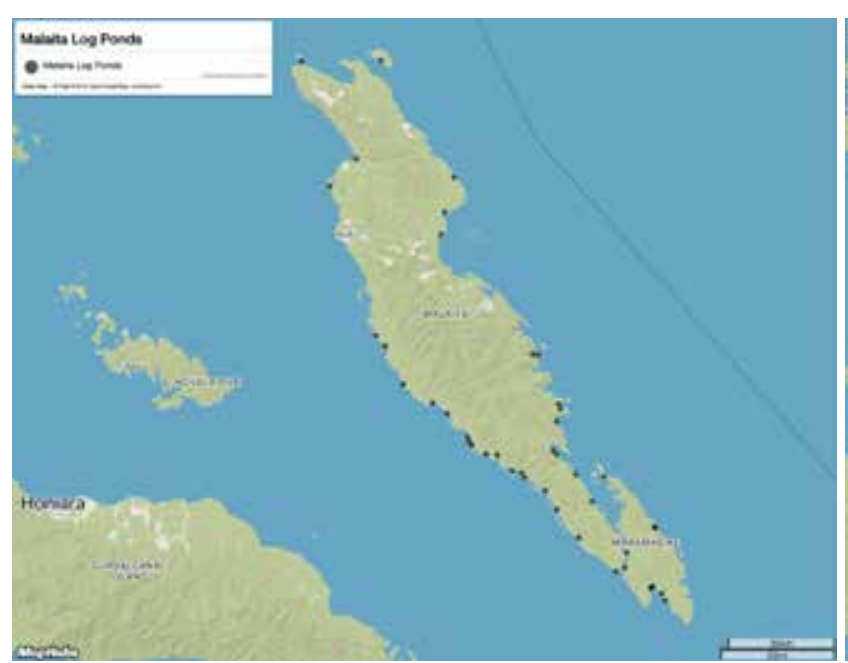

Figure 1. Distribution of log ponds on Malaita, 2019. Source: Maphubs 2019

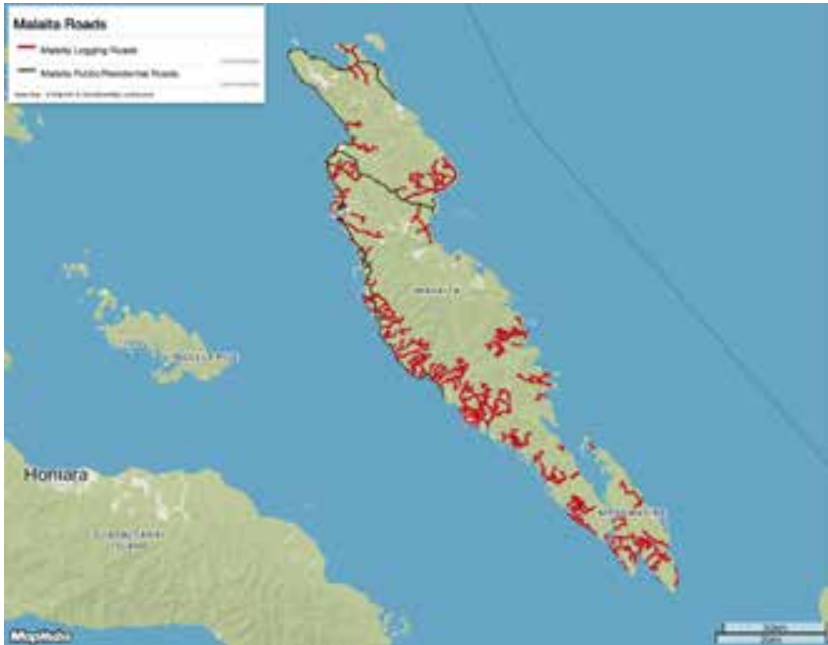

Figure 2. Logging roads (red) and public roads (black) on Malaita, 2019.

Source: Maphubs 2019 
resources, as well as the way in which the patriarchal nature of the logging industry compounds exploitative gender relations. These impacts, however, generally remain undiscussed and unaddressed.

A main aim of the National Forest Policy is to turn currently unsustainable logging practices into sustainable forest management by improving monitoring and law enforcement (MOFR 2020, 5). The policy puts specific emphasis on improving the social outcomes of logging practices, and highlights the importance of multi-sectoral stakeholder participation and respect for culture and human rights (Principle 6). Moreover, it aims to promote capacity building for gender equity and community empowerment (Goal 6). The new National Forest Policy thus offers an important avenue for positive change with regards to the social impacts of logging, and the impacts on women and girls in particular.

\section{Ten ways in which logging negatively affects women and girls}

Women and girls are negatively affected by logging operations in Solomon Islands in ten major ways. Below, these are summarized into three main categories: benefits, subsistence and safety. The accompanying quotes from interviews conducted on Malaita demonstrate women's first-hand experiences with these issues.

\section{Benefits}

1. Systematic exclusion of women from decision making. The masculine character of the logging industry itself, and discriminatory gender norms surrounding land rights and decision-making processes regarding land and natural resources, work together towards the systematic exclusion of women from decision making on logging. As a result, women are typically not present at Timber Rights Hearings, where the decision to allow or reject a proposed logging operation is made; neither are they involved in logging negotiations, agreement making or operation management.

\section{"One thing that I do not like about logging is this. Is it prohibited to let us women be part of the committees or the agreements? Logging comes to everyone, men and women, so why can we not be part of it?" (Woman from East Malaita)}

2. Royalties go only to (elderly) men. Due to a combination of women's exclusion from decisions surrounding logging and elite capture, royalties are generally only distributed among a select group of (elderly) men. Both men and women commonly state that royalties are spent on "drinking sprees" and "mistresses", often resulting in marital problems. Women thus lack control over the financial proceeds of forest exploitation and find that these proceeds often work to their disadvantage rather than to their benefit.

\section{"When the [logging] machines work, corruption comes in Only the committee members benefit from the logging. When our committee chairman received the money, he opened an account for us landowners in Honiara [the national capital], but when he came back, all the money was finished to the last coin: it went to motels, drinking and women." (Woman from West Malaita)}

3. Jobs in logging rarely benefit women. Logging employees are almost exclusively male. However, because logging wages are low, often delayed, always temporary and commonly spent on alcohol, they do not structurally contribute to household income. Also, when husbands engage in full-time logging, women's workload in their gardens and at home increases. Only few women work as cooks and cleaners in logging camps, some of whom are minors.

\section{Subsistence}

4. Loss of women's fishing grounds. The currently unsustainable logging practices severely impact fisheries, which is a core component of the rural subsistence economy. Mangroves are women's main fishing grounds, and are particularly important for gathering shells. However, mangroves near logging operations are damaged by sedimentation and oil pollution as a result of upstream logging activities. Crucially, log ponds are often constructed by clearing mangroves (Figure 3), resulting in a definitive loss of women's fishing grounds.

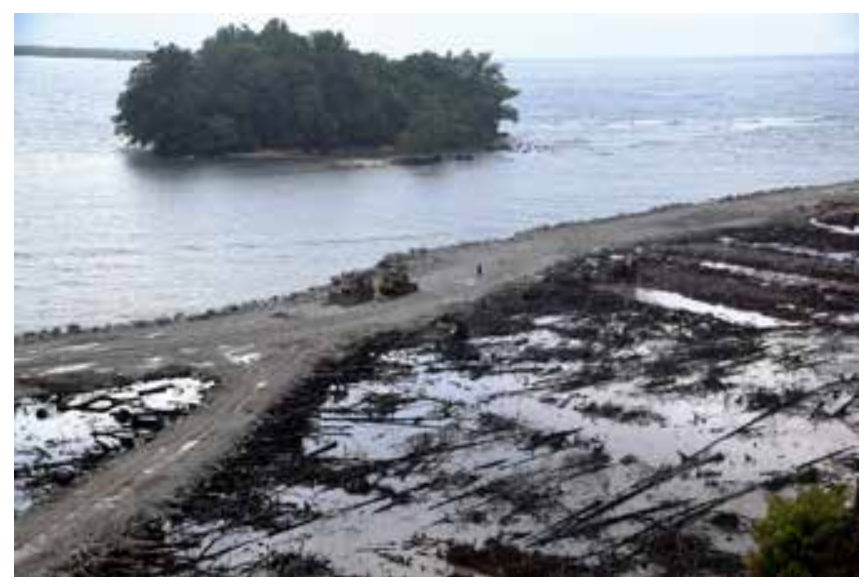

Figure 3. Mangroves, women's foremost fishing ground, are being cut down to create a log pond in East Malaita, 2017.

Photo by Jan van der Ploeg/University of Wollongong 
"It is a big concern for me that the mangroves are gone because that is the place where I found food. When my children were small, I would go there to find food for all of them: it was close by, so when I heard them cry, I could just go back quickly. [...] So when I saw the [logging] machines landing, I felt as if I saw my mother dying. I cried. The happiness, the food and the help that the place gave me, are now gone." (Woman from East Malaita)

"The mangrove area is gone for good. [... W We used to just collect shells in the mangroves for our late afternoon snacks, but our happy hour became a hungry hour!"

(Woman from East Malaita)

5. Increased weeds and pests. Logging operations also negatively impact another core component of rural subsistence, the cultivation of root crop, vegetable and fruit gardens. These fields are predominantly tended by women, who commonly report the increased presence of weeds and pests in gardens inside logging areas. The fast spread of invasive species across Solomon Islands, including the Giant African Snail (Achatina fulica), is indeed attributable to the movement of logging machinery between mainland Southeast Asia and Solomon Islands (Kiddle et al. 2017).

6. Unsafe water. The great majority of rural Solomon Islanders depend on open water sources and communal water pipes leading from the forest down to villages. As a result of poor logging practices, sedimentation and oil spills very commonly pollute these open sources, while logging machinery regularly damages water pipes. Companies rarely take responsibility for these problems, which disproportionately affect women and girls. Being tasked with fetching water, they consequentially have to walk or canoe to more distant sources, which often is coupled with safety issues.

7. Decreased food and nutrition security. The above impacts of logging on subsistence activities threaten food and nutrition security. Given that shellfish and garden products form key components of daily meals and are mainly provided by women, this increases women's burden to meet their families' needs. In a sub-sample of 78 people, a quarter (33\% of the women and $17 \%$ of the men) said that the damage that logging causes to fishing grounds reduced their families' consumption of fish and shellfish, often until well after logging operations ended.

\section{Safety}

8. Increased alcohol consumption. Logging operations are invariably associated with increased availability and excessive consumption of alcoholic beverages, notably beer. Logging companies facilitate the local sale of beer by allowing its transportation on logging barges to supply village bottle shops; it is among the main items purchased with logging wages. Increased alcohol consumption further exacerbates the already high occurrence of gender-based violence. It also causes conflicts between landowners and logging companies, as well as among landowners, to easily escalate.
"Alcohol is disturbing the whole community now. Before logging [began], drinking would only happen when it was time to celebrate, but now it happens Monday to Sunday. The young and the old, everyone drinks, and it happens everywhere too. Before, drinking would happen at the edge of the village, now it happens in the middle of it, within the view and hearing of children, who see and hear all the swearing and the fighting [...] Women get frustrated too when their husbands spend all the money they earn on beer. So, to get it balanced, they also start drinking. And then a lot of fighting happens inside the house and the children don't know where to run to anymore."
(Woman from West Malaita)

9. Sexual abuse. Sexual exploitation is a well-known and recurring problem in logging concessions. Abusive sexual encounters between incoming logging staff and local girls and women mostly happen in logging camps and on log ponds (Herbert 2007; Allen et al. 2013, 23; IOM 2019). In addition, women report being pressured to provide sexual favours to logging staff in return for these staff helping to transport land owners' timber. Logging operations are thus associated with an increase in unwanted (teenage) pregnancies, single mothers, and children growing up fatherless, as expatriate logging staff commonly stay in Solomon Islands temporarily. There are few effective means to seek justice in sexual abuse cases. This is especially so in rural areas, where logging operations take place, and where there are less trained care providers, police are less likely to be trained to handle abuse cases, and there are few formal justice options (ADB 2015).

"Here in [our village] alone we have around five [babies born from sexual encounters with expatriate logging staff], but the fathers are already gone." (Woman from West Malaita)

"There is security on the log pond, but they don't pay attention to the girls [...]. They are paid to protect the machines, so that's what they do, but nobody protects our girls." (Woman from West Malaita)

10. Health risks. As preventive healthcare and awareness of sexually transmitted diseases (STDs) is limited in logging concessions and in rural areas more generally, the sexual encounters between logging staff and local women and girls pose a health risk. This is especially so because expatriate logging employees are 
generally highly mobile. Many have previously worked in logging concessions in the Amazon, Central Africa and Southeast Asia. If they have engaged in unprotected sex there, the risk of STD transmission is significant (World Bank 2017, 25, 56; IOM 2019, 46).

\section{Conclusions and recommendations}

Logging operations in Solomon Islands negatively affect women's well-being. By structurally excluding women and girls from decision making and benefit sharing, by undermining subsistence livelihoods, and by facilitating excessive alcohol consumption and sexual exploitation, the logging sector increases already alarming gender disparities.

The recommendations below are aimed at increasing gender sensitivity and gender equity in forestry legislation, policy and practice, in line with the gender policies listed earlier in this brief.

\section{The recommendations are directed at:}

- National and regional law and policy makers: who are called upon to use these recommendations as guidance in making both existing and new forestry legislation and policy more gender sensitive. The ongoing review of the FRTUA offers a key opportunity for doing so.

- The logging sector, including the logging industry itself, and the responsible ministries: who are urged to use the recommendations to critically examine and redirect logging practices, operation monitoring and company management in light of impacts on women and girls.

- Local, national and international organizations promoting gender equity: who could take advantage of the recommendations to underpin their advocacy work on women's rights.

- Solomon Islander women and men living in logging areas: who could use the recommendations to hold logging companies, government and customary authorities accountable, as well as to take charge of making logging negotiations, agreements and practices gender equitable.

- International organizations working towards sustainable timber production: who are encouraged to use the recommendations to further develop their own criteria and indicators on gender equity, in the context of timber certification and VPA-FLEGT negotiations.

These recommendations have been formulated based on the insight that: (a) much progress can be achieved through the effective enforcement and implementation of existing legislation and policy; and (b) expansion of legislation and policy is also required to address specific issues.

\section{Implement, enforce and expand existing environmental and forestry laws and policies}

Unregulated as they currently are, logging operations increase women's burden to provide food and water, and also undermine the subsistence economy more generally. None of these issues would occur if existing laws and policies were implemented and enforced. It is therefore vital to:

a. Enforce the FRTUA and the Environment Act, implement the Logging Code of Conduct, and hold companies accountable.

Improved monitoring of logging operations and enforcement of the existing legal and policy framework should put an end to the cutting down of mangroves to create log ponds; the smothering of reefs and mangroves by sediment washing downhill from unpaved logging roads and heavily eroded river banks; improper disposal of oil and fuel; the destruction of water systems during logging road construction and felling activities; and the spread of invasive species by logging machinery.

While women and girls are disproportionately affected by the negative impacts of logging operations, they receive the least of the benefits. This is because women's concerns are not heard and addressed in key decision-making processes surrounding logging operations, notably during Timber Rights Hearings, the drafting of Logging Agreements, Environmental-Social Impact Assessments, and benefit-sharing negotiations between landowners and companies. Women are also rarely members of the committees that manage logging operations on behalf of the landowners.

In order to reverse the marginalization of women and girls in the management of logging operations and royalties, and make their needs and concerns heard and addressed, it is necessary to:

b. Make it a legal requirement that women can meaningfully participate in all logging-related negotiations, decision-making processes and operations management, including Environmental and Social Impact Assessments, Timber Rights Hearings, benefitsharing negotiations and landowner committees.

Ensuring that women's participation is meaningful will require:

- Designing locally effective and appropriate mechanisms and safe spaces for women and 
girls to voice their needs and concerns, and to highlight the types of benefits they seek from logging operations. This could involve conducting gender-specific consultations, setting quotas for minimal female representation in decision-making bodies, and/or the active involvement of women's organizations. However, to prevent women's participation resulting in negative consequences for their safety, alternative forms of representation may be needed, depending on women's own preferences.

- Taking into account the diversity of concerns, needs and aspirations present among different groups of women. These may vary depending on women's age, marital status, wealth, religion and ethnicity.

c. Make it a legal requirement that the outcomes of decision-making processes are formalized, transparent, understandable and accessible for all women and men affected.

d. Support and expand the capacity of the Public Solicitor's Office to ensure that accessible and safe grievance mechanisms exist for both women and men in and around logging operations.

\section{Implement, enforce and expand existing women's rights legislation and policies}

Logging operations heighten women's and girls' vulnerability by facilitating sexual exploitation, excessive alcohol consumption, and an associated increase in family violence.

These injustices are in direct conflict with the laws and policies listed earlier in this brief, to which the Solomon Islands Government is committed. Preventing and addressing these issues requires:

a. Enforcement of the Family Protection Act, which criminalizes physical, sexual, psychological and economic abuse, or the threat of such abuse, between people in any type of intimate relation of any duration.

Under this Act, any exploitative or abusive sexual relation between logging employees and local women and girls is illegal, and should be addressed accordingly. In addition to the individual perpetrators, logging companies should also be held accountable for the behaviour of their employees. Ride and Soaki $(2019,46-50)$ and Ride and Kii $(2018,45)$ offer further recommendations on improving family violence service provisioning, and addressing alcohol abuse; while IOM (2018, 53-55) offers specific recommendations on family violence service improvement in logging areas. b. Expansion of existing legislation, in line with the National Gender Equality and Women's Development Policy, and the National Policy to Eliminate Violence Against Women and Girls.

These policies aim to: provide quality services for women and girls in rural areas; strengthen legal frameworks, law enforcement and the justice system; improve medical, protective and legal services; and hold perpetrators accountable. As part of this policy framework, it is recommended that:

- It becomes a legal obligation for logging operations to be accompanied by independently-organized social support programmes. These should involve training police, teachers, health practitioners, women's groups, customary and church leaders to detect and respond to sexual exploitation, alcohol abuse and family violence, and provide community awareness campaigns on sexual health.

- It becomes legally prohibited for logging companies and their employees to transport alcoholic beverages on logging barges, ships and vehicles.

\section{Acknowledgments}

This research was funded through the European Union's Horizon 2020 research and innovation programme under Marie Skłodowska-Curie grant agreement No. 748242 and the ADB project 'Strengthening Community Based Resource Management to Safeguard Food Security in Malaita Province, Solomon Islands' (SOL-7753) under the CGIAR Research Program on Fish Agri-Food Systems (FISH). This info brief was published as part of the CGIAR Research Program on Forests, Trees and Agroforestry (FTA), led by CIFOR, and has gone through CIFOR's standard peer-review procedure. Valuable feedback on earlier versions of the manuscript was provided by Markus Ihalainen, Anouk Ride, Paolo Cerutti, Terry Sunderland and multiple colleagues of the Leiden Institute for Cultural Anthropology and Development Sociology.

\section{Further reading}

FSC (Forest Stewardship Council). 2016. Promoting Gender Equality in National Forest Stewardship Standards. FSCGUI-60-005 V1-0. Bonn: FSC International.

ITTO (International Tropical Timber Organization). 2018. Policy Guidelines on Gender and Empowering Women. Yokohama: ITTO.

United Nations. 2011. Guiding Principles on Business and Human Rights. Implementing the United Nations 'Protect, Respect and Remedy' Framework. New York: United Nations Human Rights Office of the High Commissioner. 


\section{References}

ADB (Asian Development Bank). 2015. Solomon Islands Country Gender Assessment. Manila: ADB.

Allen MG, Dinnen S, Evans D. and Monson R. 2013. Justice delivered locally. Systems, challenges and innovations in Solomon Islands. Washington DC: World Bank.

FAO and SPC (Food and Agriculture Organization and the Secretariat of the Pacific). 2019. Country Gender Assessment of Agriculture and the Rural Sector in Solomon Islands. Rome/ Noumea: FAO/SPC

Herbert T. 2007. Commercial sexual exploitation of children in the Solomon Islands: A report focusing on the presence of the logging industry in a remote island. Solomon Islands: CCC Church of Melanesia.

IOM (International Organization for Migration). 2019.

Community health and mobility in the Pacific: Solomon Islands Case Study. Honiara: IOM.

ITTO (International Tropical Timber Organization). 2019. Biennial review and assessment of the world timber situation 2017 2018. Yokohama: ITTO.

Kabutaulaka T. 2000. Rumble in the Jungle: Land, culture and (un)sustainable logging in Solomon Islands. In Hooper A (ed.) Culture and sustainable development in the Pacific. Canberra: Asia Pacific Press. 88-97.

Katovai E, Katovai DD and Laurance WF. 2021. Potential Restoration Approaches for Heavily Logged Tropical Forests in Solomon Islands. In Shaping the Future of Small Islands. Singapore: Palgrave Macmillan. 219-232.

Kiddle L, Stronge D and Pennay M. 2017. Giant African Snails: Devastating gardens and livelihoods in Solomon Islands. Devpolicy Blog. The Development Policy Centre.

Minter T, Orirana G, Boso D and van der Ploeg J. 2018. From happy hour to hungry hour. Logging, fisheries and food security in Malaita, Solomon Islands. WorldFish Report 2018 07. Penang, Malaysia: WorldFish.

MOFR (Ministry of Forestry and Research). 2020. National Forest Policy. Honiara: MOFR.

MWYCFA (Ministry of Women Youth Children and Family Affairs). 2016. Gender equality: Where do we stand? Noumea: Secretariat of the Pacific.

Osifelo E. 2021. 'Cut, Cut, Cut'. Honiara: Island Sun. https:// theislandsun.com.sb/cut-cut-cut/

Ride A and Soaki P. 2019. Women's Experiences of Family Violence Services in Solomon Islands. Honiara: Australian Aid/ Solomon Islands Government.

Ride A and Kii M. 2018. Stretim: Attitudes and Communication about Violence Against Women and Girls in Solomon Islands. Honiara: Ministry of Women Youth Children and Family Affairs. Scheyvens R and Lagisa L. 1998. Women, disempowerment and resistance: An analysis of logging and mining activities in the Pacific. Singapore Journal of Tropical Geography 19(1):51-70.

Schwarz AM, Andrew N, Govan H, Harohau D, Oeta J. 2013. Solomon Islands Malaita Hub Scoping Report. CGIAR Research Program on Aquatic Agricultural Systems. Project Report AAS2013-18. Penang: WorldFish

SPC (Secretariat of the Pacific Community). 2018. Gender analysis of the fisheries sector: Solomon Islands. Noumea: SPC.

UN (United Nations) Human Rights Council. 2021. Report of the Office of the United Nations High Commissioner for Human Rights. Compilation on Solomon Islands. A/HRC/WG.6/38/ SLB/2. New York: UN.

World Bank. 2019. Enhancing the economic participation of vulnerable young women in Solomon Islands. Community access and urban services enhancement project. Washington DC: World Bank.

World Bank. 2017. Solomon Islands systematic country diagnostic priorities for supporting poverty reduction and promoting shared prosperity. Washington, DC: World Bank.

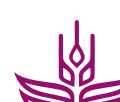 \\ GENDER Platform \\ This work has been carried out under the CGIAR GENDER Platform, which is grateful for the support of CGIAR Trust Fund Contributors. www.cgiar.org/funders}

\begin{tabular}{|l|l}
\hline CGIAR & $\begin{array}{l}\text { RESEARCH } \\
\text { PROGRAM ON } \\
\text { Forests, Trees and } \\
\text { Agroforestry }\end{array}$ \\
\cline { 1 - 2 }
\end{tabular}

The CGIAR Research Program on Forests, Trees and Agroforestry (FTA) is the world's largest research for development program to enhance the role of forests, trees and agroforestry in sustainable development and food security and to address climate change. CIFOR leads FTA in partnership with ICRAF, the Alliance of Bioversity International and CIAT, CATIE, CIRAD, INBAR and TBI.

FTA's work is supported by the CGIAR Trust Fund: cgiar.org/funders
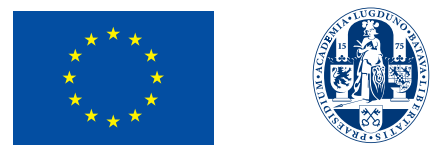

Universiteit

Leiden

The Netherlands 